\title{
Virulence characterization and clonal analysis of uropathogenic Escherichia coli metallo-beta-lactamase-producing isolates
}

Fatemeh Zanganeh Matin

Shahid Chamran University of Ahvaz

Seyedeh Elham Rezatofighi ( $\sim$ e.tofighi@yahoo.com)

Shahid Chamran University of Ahvaz https://orcid.org/0000-0003-1373-7346

Mohammad Roayaei Ardakani

Shahid Chamran University of Ahvaz

Mohammad Reza Akhoond

Shahid Chamran University of Ahvaz

Fahimeh Mahmoodi

Shahid Chamran University of Ahvaz

Research

Keywords: Uropathogenic Escherichia coli, Urinary tract infection, Metallo-beta-lactamase, Carbapenemase, Carbapenem resistance, Antimicrobial resistance, Virulence, blaNDM, blaOXA-4

Posted Date: May 6th, 2021

DOI: https://doi.org/10.21203/rs.3.rs-487467/v1

License: @ (i) This work is licensed under a Creative Commons Attribution 4.0 International License. Read Full License

Version of Record: A version of this preprint was published at Annals of Clinical Microbiology and Antimicrobials on August 3rd, 2021. See the published version at https://doi.org/10.1186/s12941-021-00457-4. 


\section{Abstract}

\section{Background}

Uropathogenic Escherichia coli (UPEC) is a major cause of urinary tract infection (UTI); however, treatment of this disease has been associated with problems due to increased antimicrobial resistance (AMR). One of the most important types of AMR is carbapenem resistance (CR). CR bacteria are known as an important challenge to global public health today. Class B metallo-beta-lactamases (MBLs) are one of the major factors for resistance against carbapenems. We aimed to investigate the characteristics of UPEC isolates producing MBL.

\section{Methods}

A cross-sectional study was conducted from October 2018 to December 2019 in Ahvaz; Iran. Urine samples of patients with UTI were collected and UPEC isolates were identified by biochemical and molecular methods. Metallo-beta-lactamase-producing isolates were detected using modified carbapenem inactivation method ( $\mathrm{mCIM}$ ) and EDTA-CIM (eCIM) tests. MBL genes, phylogenetic group, and virulence genes profile of carbapenem resistant isolates were determined. Conjugation assay and plasmid profiling were conducted to evaluate the ability of transferring of CR to other $E$. coli isolates. Clonal similarity of isolates were assessed using Enterobacterial intergenic repetitive element sequence (ERIC)-PCR.

\section{Results}

Among 406 UPEC isolates, 12 (2.95\%) carbapenem-resistant were detected of which 11 were phenotypically MBL-producing. Four isolates were resistant to all antimicrobial agents and were considered possible pandrug-resistant (PDR). bla $a_{\mathrm{NDM}}, b / a_{\mathrm{OXA}-48}, b / a_{\mathrm{IMP}-1}$, and $b / a_{\mathrm{IMP}-2}$ genes were found in $9,5,1$, and 1 isolates, respectively. Among 30 virulence genes investigated, the traT, fyuA followed by fimH, and iut $A$ with the frequency of 8 (66.7\%), 8 (66.7\%), 7 (58.3\%), and 7 (58.3\%) were the most identified genes, respectively. Siderophore production was the main virulence trait among carbapenem-resistant UPEC isolates. Except for two, all other isolates showed weak to moderate virulence index. In all recovered isolates, CR was readily transmitted via plasmids to other isolates during conjugation experiments.

\section{Conclusion}

MBL and carbapenemase genes, especially $b / a_{\mathrm{NDM}}$ and $b / a_{\mathrm{OXA}-48}$ are spreading rapidly among bacteria, which can be a threat to global public health. Therefore monitoring the emergence and dissemination of new AMR is necessary to continuously refine guidelines for empiric antimicrobial therapy. Understanding the mechanisms of resistance and virulence in this group of bacteria can play an effective role in providing new therapeutic methods.

\section{Introduction}

Urinary tract infection (UTI) is one of the most common infectious diseases that affects people of all ages. The main etiologic agent causing UTI is a group of Escherichia coli strains that named uropathogenic Escherichia coli (UPEC) [1]. UPEC is a subgroup of extraintestinal pathogenic E. coli (ExPEC) which is differentiated from intestinal E. coli strains. UPEC strains are capable to colonize and invade to urogenital tract which eventually leading to infection of urinary tract system. Disease establishment is caused by virulence factors (VFs) of bacteria and host characteristics [2, 3]. Various VFs have been introduced for UPEC including invasins, adhesions, toxins, iron-acquisition systems, and serum resistance factors [4]. VFs may be present in the chromosome or acquired horizontally through mobile genetic elements such as transposons, plasmids, and pathogenicity islands, thereby leading great diversity among UPEC strains $[5,6]$.

Antimicrobial therapy usually is the first strategy in treating a UTI. The choice of antimicrobial compound depends on the patient's health condition and the type of bacteria causing the UTI. However, due to overuse of antibiotics, antimicrobial resistance (AMR) has greatly expanded among bacteria. Many E. coli strains, especially UPEC have become multi-, extensively- or pan-drug resistant (MDR, XDR, or PDR) [7, 8]. This poses a great challenge in the treatment of UTI infections. Therefore, monitoring the emergence and dissemination of new AMR is necessary to continuously refine guidelines for empiric antimicrobial therapy $[1,9]$. Resistance against trimethoprim-sulfamethoxazole, fluoroquinolones, and beta-lactams is increasing among UPEC isolates [2, 10, 11]. Carbapenems such as imipenem, meropenem, and doripenem are stable antibiotics against extended-spectrum $\beta$-lactamases (ESBLs) and AmpC $\beta$ lactamases [12] and considered as a last-resort drugs for treating infections by MDR bacteria. However extensive use of carbapenems has led to the emergence of carbapenem-resistant Enterobacteriaceae (CRE) [12]. CRE are known as a global clinical and public health problem because their infections are resistant to most classes of antibiotics including trimethoprim-sulfamethoxazole, fluoroquinolones, and beta-lactams so-called superbugs. CRE are associated with high mortality due to limited treatment options [12-14].

Several mechanisms have been proposed for resistance against carbapenems in Enterobacteriaceae. Production of carbapenemases that are categorized in Ambler classification as follows: class A Klebsiella pneumonia carbapenemase (KPC), class B metallo-beta-lactamase (MBL) including New Delhi metallobeta-lactamase (NDM), imipenemase (IMP), and Verona integron-encoded metallo-beta-lactamase (VIM), as well as class D oxacillinases (OXA). Moreover, over-expression of ESBLs, AmpC enzymes and efflux pumps combined with porin loss can also lead to carbapenem resistance (CR) [12,15-17]. Carbapenemase genes are predominantly located on plasmids and are transmitted to other bacteria or integrated into chromosomes [16].

In the present study we aimed to investigate the antimicrobial susceptibility pattern and presence of MBL-producing among UPEC isolates. As the information on the virulence characteristics of MBL-producing UPEC isolates is very limited, the virulome, phylogenetic groups, clonal relationship, and mechanism of CR transfer among these isolates were investigated.

\section{Materials And Methods}




\section{Ethics}

The ethics of the study was confirmed by the Ethics Committee of Shahid Chamran University of Ahvaz according to Declaration of Helsinki (EE/98.24.3.26336/scu.ac.ir). Before collecting information, participants or parents (for children cases) were asked to read, accept and sign an informed consent form

\section{Sample collection and identification}

A cross-sectional study was performed from October 2018 to December 2019. The sample size was estimated using a single population proportion formula based on the prevalence of 0.15 [1], $95 \%$ confidence interval, and margin error of $5 \%$. With considering a $10 \%$ non-response rate, the minimum samples size was 225 ; however, to be conservative we collected 427 samples.

The samples were obtained from hospitals and laboratories in Ahvaz city; Iran. E. coli isolates of patients who had recently consumed antimicrobial drugs were excluded from the study. Briefly, the isolates were cultured onto MacConkey (Biolife Italiana; Italy) and Eosin Methylene Blue (EMB, Merck; Germany), and subsequently were incubated at $37^{\circ} \mathrm{C}$ for $24 \mathrm{~h}$. Lactose-fermenting colonies on MacConkey, or colonies with metallic sheen on EMB were investigated by conventional biochemical tests including production of lysine decarboxylase, oxidase, Sulfur Indole Motility (SIM), Simmon's Citrate and Methyl Red / VogesProskauer (MR/VP). Finally, purified isolates were analyzed by PCR for the presence of uspA gene, which is the highly specific gene of $E$. coli. Detection of uspA gene was performed as described previously [18].

\section{Antimicrobial susceptibility pattem}

Kirby-Bauer disc diffusion method was performed to evaluate the resistance and susceptibility of isolates to antimicrobial agents recommended by Clinical \& Laboratory Standards Institute 2018 (CLSI-2018) [19]. The antimicrobial discs included Nalidixic-acid, Ampicillin, Tetracycline, Streptomycin, Sulfamethoxazole-trimethoprim, Ciprofloxacin, Kanamycin, Gentamycin, Fosfomycin, Imipenem, Meropenem, Cefotaxime, Ceftazidime, Cefazolin, and Nitrofurantoin. The isolates resistance to three or more different antimicrobial families were considered multidrug resistant (MDR).

As meropenem or imipenem resistant UPEC isolates were the focus of present study, the resistant isolates were subjected to further analyses. The minimum inhibitory concentration (MICs) for imipenem or meropenem were determined as recommended by CLSI-2018. MIC breakpoints for both antibiotics were defined $\geq 4 \mu \mathrm{g} / \mathrm{ml}$.

\section{Combined-disc (CD) and double disc synergy (DDS) tests}

Phenotypic CD and DDS tests were performed to identify MBL-producing isolates. For CD test, two discs of imipenem (10 $\mu \mathrm{g})$ and imipenem-EDTA (10 $\mu \mathrm{g}$ $1460 \mu \mathrm{g}$ ) were placed on the Muller-Hinton agar (MHA; Biolife Italiana; Italy) inoculated by 0.5 -McFarland test isolates. After incubation of the plates at $35^{\circ} \mathrm{C}$ for 16-18 h, the inhibition zone around discs were measured. The isolates were considered MBL-producer when the diameter of inhibition zone around the imipenem-EDTA disc increased by $\geq 7 \mathrm{~mm}$ compared to imipenem disc alone [20].

For DDS test, two discs of imipenem and EDTA $(1460 \mu \mathrm{g})$ were placed on MHA plates inoculated with test isolates. The distance between two discs was considered $15 \mathrm{~mm}$. After incubation of the plates at $35^{\circ} \mathrm{C}$ for $16-18 \mathrm{~h}$, the zone around discs were measured. Increasing of the inhibition zone or the formation of a phantom zone between the two discs indicated the MBL production [20].

\section{Modified carbapenem inactivation method (mCIM) and EDTA-CIM (eCIM)}

Either $\mathrm{mCIM}$ and eCIM tests are extensively used for the epidemiological or infection prevention aims. The mCIM test could identify the bacteria that produce all carbapenemases, while the eCIM test was performed to differentiate MBL-producers from the serine carbapenemases. To perform $\mathrm{mCIM}, 1 \mu \mathrm{L}$ loopful of the isolates were emulsified in $2 \mathrm{~mL}$ of tryptone soya broth (TSB). Then, one meropenem disc was immersed in the suspension for 4 hours at $37^{\circ} \mathrm{C}$. A MHA plate was inoculated by 0.5-McFarland standard E. coli ATCC25922. Meropenem disc was removed from the suspension and excess liquid was expelled. Meropenem disc was placed on the inoculated plate and incubated at $37^{\circ} \mathrm{C}$ for 24 hours. Inhibition zone diameter of $6-15 \mathrm{~mm}$ or appearance of pinpoint colonies within a $16-18 \mathrm{~mm}$ zone around imipenem disc indicate the presence of carbapenemase [19].

eCIM test was performed when the $\mathrm{mCIM}$ test was positive. This test was done as similar to $\mathrm{mCIM}$, except that after adding test isolate to the TSB, $20 \mu \mathrm{L}$ of 0.5 M EDTA was added; then meropenem disc was immersed. Meropenem discs of eCIM and mCIM tests were placed on one plate and analyzed simultaneously. An increase of $\geq 5 \mathrm{~mm}$ in inhibition zone for eCIM versus $\mathrm{mCIM}$ was considered MBL-positive, while no change in zone diameter or an increase of $\leq 4 \mathrm{~mm}$ indicated the presence of carbapenemase [19].

\section{Phenotypic differentiation of MLBs and class A KPC carbapenemases}

To differentiate MBLs- and class A KPC carbapenemase-producing isolates, phenyl boronic acid (PBA) disc test was applied. The test was performed as a combined-disc of meropenem with and without PBA. Phenyl boronic acid was dissolved in dimethyl sulfoxide (DMSO) at a concentration of $20 \mathrm{mg} / \mathrm{mL}$. Then meropenem disc was inoculated by $20 \mu \mathrm{L}$ of PBA solution (400 $\mu \mathrm{g}$ PBA/disc). The test was performed as given for the standard disc diffusion method. An increase of $\geq 5 \mathrm{~mm}$ in inhibition zone around meropenem-PBA disc versus meropenem was considered class A KPC carbapenemase producer [21, 22].

\section{Detection of resistance genes}

Imipenem or meropenem-resistant isolates were analyzed for the presence of MBL-genes including $b / a_{\mathrm{VIM}-1}, b / a_{\mathrm{VIM}-2}, b / a_{\mathrm{IMP}-1}, b / a_{\mathrm{IMP}-2}, b / a_{\mathrm{SPM}-1}, b / a_{\mathrm{NDM}}, b / a_{\mathrm{SIM}}$, and $b / a_{\mathrm{GIM}}$. The other $\mathrm{CR}$ genes of $b / a_{\mathrm{KPC}}, b / a_{\mathrm{OXA}-23}$ and $b / a_{\mathrm{OXA}-48}$ were also investigated. Genomic DNA of isolates was extracted using the boiling lysis 
procedure. PCR reactions were performed as previously described [23-30].

\section{Virulence genotyping and phylogenetic grouping}

The isolates were assayed for the presence of 30 virulence traits using five multiplex-PCR panel as previously described [31]. The investigated VGs were including papEF, papA, fimH, papG allele I-III, papG allele I, papG allele II, papG allele III, kspMTIII, gafD, focG, sfa/focDE, nfaE, papC, afa/draBC, sfaS, bmaE, $i b e A$, traT, cvaC, cdtB, hlyA, cnf1, fyuA, chuA, iutA, K1,K5, kpsMTIl, and $r f c$. Determination of four major $E$. coli phylogroups was performed based on the triplex PCR as described by Clermont et al [32]. According to the presence of two genes of chuA and $y j a A$, and TSPE4.C2 DNA fragment, the isolates assigned to one of $A, B 1, B 2$, or D phylogenetic groups.

\section{Enterobacterial intergenic repetitive element sequence (ERIC)-PCR}

Fingerprinting of imipenem or meropenem resistant isolates was performed using ERIC-PCR based on conditions and primers described previously [33]. To evaluate the relationship between isolates, the presence or absence of bands compared to the standard DNA molecular marker was assessed. The clustering of the isolates was done based on Unweighted Pair Group Method with Arithmetic Mean (UPGMA) analysis using the SAHN NTSYS program version 2.02e. A Dice similarity index was used for the definition of ERIC clusters.

\section{Plasmid profiling and conjugation}

Carbapenem resistant isolates were assayed for plasmid content. Plasmids were extracted using alkaline lysis method [34], then electrophoresed on agarose gel (1\%). Estimation of plasmid sizes was acquired using a molecular weight marker, made from a lambda/ Hind III digest.

The MBLs- or carbapenemase-producing isolates were conjugated with a lactose-negative enteroinvasive $E$. coli (EIEC) strain that was susceptible to imipenem and meropenem. The donors and recipient bacteria were cultured in nutrient broth for 16 hours; then mixed in a ratio of 1:10 (donor: recipient) [34]. After incubation for $48 \mathrm{~h}$ at $37^{\circ} \mathrm{C}$, the mixtures were inoculated on MCA containing imipenem or meropenem $(4 \mu \mathrm{g} / \mathrm{mL})$. The plates were incubated overnight at $37^{\circ} \mathrm{C}$. The resistant lactose-negative isolates were analyzed for the presence of inv and resistance genes via PCR reaction.

\section{Results}

\section{Antimicrobial susceptibility pattern of UPEC isolates}

Out of 427 cultured samples, 406 isolates were phenotypically and molecularly confirmed as UPEC. As defined in Table 1, the most antimicrobial resistance was against ampicillin (82.3\%) followed by cefazolin (80\%), tetracycline (59.4\%), and nalidixic-acid (59.1\%). Only 13 (3.2\%) isolates were susceptible to all antimicrobials tested and the rest (96.8\%) were resistant to at least one or more antimicrobials. MDR profile was found in 377 (92\%) isolates. The highest frequency of antimicrobial susceptibility was recorded for meropenem ( $97.5 \%)$, imipenem ( $97.3 \%)$, followed by nitrofurantoin ( $95.4 \%)$, and fosfomycin (92.4\%).

In total, 12 isolates were resistant to imipenem, meropenem or both (Table.1) and archived for further analysis. All of these isolates were XDR meaning nonsusceptible to at least one drug in all but two or fewer antibiotic or antimicrobial family [8], also 4 (1\%) isolates were possible PDR meaning were nonsusceptible to all investigated antimicrobial categories [8].

\section{Phenotypic detection of MBL-producing UPEC isolates}

In total, 9 isolates were confirmed by disc diffusion and MIC to be resistant against imipenem and meropenem, however, 2 and 1 isolates were only resistant against imipenem and meropenem, respectively. To detect MBL-producers, CDT, DDST, and mCIM-eCIM were done. We found that 2 and 6 UPEC isolates were positive for $C D$, or both CD, DDS tests, respectively; while four UPEC isolates were negative in both tests (Table 2 and Fig 1).

Phenotypically tests of $\mathrm{mCIM}$, eCIM were used to detect and differentiate MBLs from serine carbapenemases. Out of 12 resistant UPEC isolates, 11 were positive by mCIM-eCIM tests, while one isolate was negative by eCIM. Details of results are presented in Table 2 and Fig 1.

\section{Phenotypic detection of KPC-producing UPEC isolates}

PBA disc test was applied to detect class A KPC-producing isolates. Two isolates were phenotypically positive by this test and were considered KPC-producing UPEC. However, these isolates were also previously detected as MBL producers (Table 2 and Fig 1).

\section{Resistance gene assays of MBL- and carbapenemase-producing isolates}

The distribution of MBLs and carbapenemase genes among UPEC isolates are shown in Table 2. Out of 12 carbapenem resistant isolates, 11 were positive for MBL genes. $b / a_{\mathrm{NDM}}, b / a_{\mathrm{IMP}-1}$, and $b / a_{\mathrm{IMP}-2}$ were found in 9,1 , and 1 isolates, respectively. Gene sequences were registered under the accession numbers of

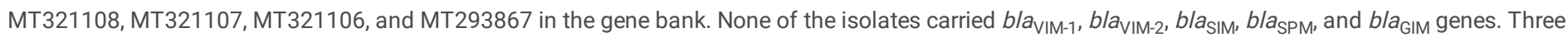
main carbapenemase genes of $b / a_{\mathrm{OXA}-48}, b / a_{\mathrm{OXA}-23}$, and $b / a_{\mathrm{KPC}}$ were investigated. bla $a_{\mathrm{OXA}-48}$ was found in five isolates while $b / a_{\mathrm{OXA}-23}$, and $b / a_{\mathrm{KPC}}$ were not detected. The simultaneous carriage of two genes blaNDM and blaOXA-48 was found in four isolates (Table 4 and Fig 1).

\section{Virulome and phylogenetic grouping}


The content of VGs for carbapenem resistant UPEC isolates is shown in Table 3. The most detected genes were traT, fyuA followed by fimH, and iutA with the frequency of 8 (66.7\%), 8 (66.7\%), 7 (58.3\%), and 7 (58.3\%), respectively. kpsMTIII, papEF, ibeA, gafD, cdtB, focG, bmaE, sfa/focDE, papG allel I, II, and III, K1, rfc, $n f a E$, sfaS, and $a f a / d r a B C$ genes were not detected among the isolates. The two UPEC isolates had none of the tested virulence genes while they showed resistance against all investigated antibiotics. According to phylogenetic grouping 5, 5, 2, and 1 isolates were B2, A, B2, and D phylogroups.

\section{ERIC-PCR}

The isolates produced PCR products with different sizes from 250 to 2500 bp and various patterns yielded 5 to 12 bands. Two isolates showed the same ERIC pattern and virulence gene profile; however the AMR patterns were different. Both of these isolated were phylogroup A. Also two isolates had approximately $95 \%$ similarity. The similarity of the other isolates was less than $80 \%$, indicating a different source of isolates. Drawn dendrogram had a matrix correlation of 0.91 .

\section{Conjugal transfer and plasmid profiling}

Conjugation test showed that imipenem or meropenem resistance could be transmitted to other bacteria; therefore, these isolates capable to disseminate $\mathrm{MBL}$ or carbapenemase genes horizontally. All 12 UPEC donors transferred carbapenem resistance phenotype to EIEC recipient strain and this strain was able to grow on the medium containing the antibiotic carbapenem. Transconjugants were positive for MBL or carbapenemase genes and inv by gene-specific PCR. Plasmid profiling showed different patterns for plasmids ranging 5 to upper $50 \mathrm{~kb}$. All isolates presented different plasmid pattern. Plasmid profiling of donors and recipients cells were not equal after conjugation, indicating that not all plasmids were transferred during conjugation.

\section{Discussion}

UTI is one of the most important bacterial infectious diseases in humans, which is mainly caused by $E$. coli. Antibiotics are commonly used to treat UTIs. However, the emergence and dissemination of AMR has posed a major challenge in the treatment of these diseases. Detection of antibiotic resistance type, its transmission mechanism, and the characteristics of resistant bacteria can be very effective in designing treatment guidelines.

Investigation of antimicrobial susceptibility profile of UPEC isolates shows high antimicrobial resistance against most of the antibiotics evaluated in this study. However, imipenem, meropenem, nitrofurantoin, fosfomycin, and to some extent gentamycin and kanamycin showed noticeable activity against UPEC isolate. Developing resistance to these antibiotics can be very challenging to the healthcare system. Other studies in Iran regarding the antibiotic resistance of UPEC isolates show almost similar profiles [35-38]. Some studies in Iran have not found resistance to imipenem or meropenem among $E$. coli isolates. More than $90 \%$ of UPEC isolates were MDR and $2.7 \%$ were possible XDR. This statistic indicates a high frequency of antibiotic resistance among these isolates. Four isolates were resistant to all studied antibiotics and therefore were considered possible PDR. The XDR and PDR Enterobacteriaceae are important because the mortality rate is high among patients infected by these bacteria [39-41]; although, some researchers disagree [42]. PDR E. coli is very rare [39]; however, in our study, four isolates (1\%) were resistant to all the antibiotics studied. Risk factors for infections with XDR and PDR E. coli isolates have not yet been identified and little information is available. Understanding the mechanisms of AMR and virulence characteristics of these pathogens helps researchers to find solutions for the long-standing AMR problem [7].

To detect MBL-producing isolates and differentiate from other carbapenemases CDT, DDST, mCIM-eCIM and PBA test were performed. Previously, Modified Hodge test was recommended as a phenotypic method for detecting carbapenemases; however, this test was excluded from the CLSI (2018) due to the inability to identify some carbapenemase-producing bacteria, including NDM-producing strains [20]. Among the tests performed in the present study, the mCIM-eCIM method was able to more effectively detect the MBL-producing isolates. MBL genes were found in all isolates identified as MBL-producers by this method. One isolate was positive by $\mathrm{mCIM}$ but negative by eCIM and also PBA disc test. Eventually it was found that this isolate carries $b l a_{0 X A-48}$ and belonged to group D carbapenemases. Although two isolates were positive for PBA disc test, but they lacked bla $a_{\text {KPC }}$ gene. These isolates were also positive for $\mathrm{mCIM}-\mathrm{eCIM}$ and both had the $b / a_{\mathrm{NDM}}$ gene. The lack of detection of $b / a_{\mathrm{KPC}}$ may be due to the inability of the primers to target this gene or the PBA disc test results were false positive.

PCR assays and sequencing of products showed that 11 isolates carry MBL genes. The predominant gene was bla $a_{\text {NDM }}$ that found in nine UPEC isolates. For the first time $b / a_{\mathrm{NDM}}$ was detected in a Swedish patient (originally from India) which traveled to New Delhi, India. In this patient, the b/a ${ }_{\mathrm{NDM}}$ was isolated from

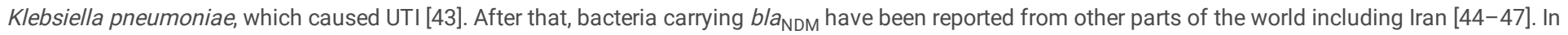

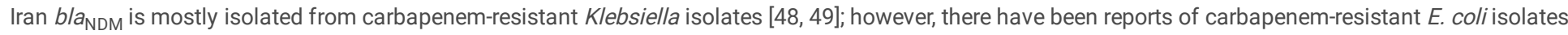
carrying this gene. [47, 50-52]. A study conducted in Ahvaz; Iran from 2014 to 2015 reported that there were no MBL-producing Enterobactericeae isolates carrying $b / a_{\text {NDM }}$ in this region [53]. However, in 2018, this gene was found in commensal E. coli and Pseudomonas aeruginosa which indicates the dissemination of this type of resistance among bacteria in Ahvaz; Iran [51, 54]. In the present study, $2.2 \%$ of UPEC isolates harbored $b / a_{\mathrm{NMD}}$; therefore, this gene is rapidly spreading among the strains of this region. Conjugation experiments showed that all b/a $a_{\text {NDM }}$ genes identified in this study are transferred by plasmids and have the ability to be transmitted to other strains. The other detected MBL genes were $b / a_{\mid M P-1}$ and $b / a_{\mid M P-2}$. Little is known about the presence of these genes among carbapenem-resistant Escherichia coli isolates in Iran. We found two reports about the presence of bla

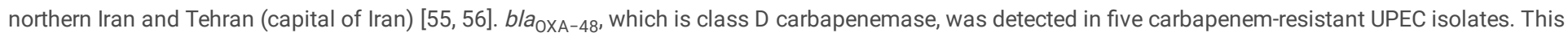
gene also seems to play an important role in carbapenem resistance among $E$. coli isolates. bla $a_{0 X A-48}$ is endemic in Iran and dissemination of this gene is mainly driven by the composite transposon Tn1999 and its variants [57].

In the present study, the co-existence of $b / a_{\mathrm{OXA}-48}$ and $b / a_{\mathrm{NDM}}$ genes was found in four UPEC isolates. However, it is not clear that these two genes are carried on a single plasmid or placed in the separate plasmids. The presence of these two genes in an isolate has been reported in several studies [15, 17, 47].

Page 5/12 
Conjugation experiments revealed that all carbapenem resistance genes were able to transfer to other isolates; however, plasmid profiling showed that these genes carried by plasmids with different sizes and probably different sequences. We could not identify the sequence and types of the plasmids which is another limitation of the present study. Complete sequencing of these plasmids can clear up many ambiguities about how they are transmitted, distributed, and their role in the resistance and virulence of pathogenic bacteria. ERIC-PCR clusters indicated that some isolates were clonally similar, but revealed different AMR profiles and different carbapenem- resistant genes that may be due to having different plasmids.

Little is known about the pathogenicity of carbapenem-resistant $E$. coli strains. Most virulence and antibiotic resistance genes, especially CR genes, are transmitted to bacteria via plasmids. However, the ability of bacteria to accept different plasmids is limited because plasmids have cost for bacteria and the energy resources are limited. It is not clear whether bacteria move toward greater resistance, greater pathogenicity, or both during their evolution. The finding of Gottig et al revealed that NDM-1 carriage and expression exerted a fitness cost and does not significantly effect on increasing the virulence [42]. Investigation of the presence of 30 virulence genes in carbapenem-resistant isolates showed that these isolates had from 0 to 10 virulence genes. No virulence gene were found in the isolates 303 and 47 (Table 4). Although they had different antibiotic resistance profile, ERIC-PCR clustering showed that they are the same clone. The isolate 4, which was considered possible PDR, had ten virulence genes; thus, this isolate had high potential virulence and antibiotic resistance at the same time. The isolate 10 also showed a strong virulence profile; however, the virulome of the rest of them reflected weak virulence.

The genes including traT, fimH, fyuA, and iut $A$ were more prevalent among $\mathrm{CR}$ isolates. However, when the frequency of virulence genes was assessed based on their function, the genes involved in iron uptake and siderophore production ( fyuA, iutA, and chuA) were highest and $75 \%$ of these isolates carried at least one of these genes. fyuA (yersiniabactin siderophore) also plays an important role in biofilm formation in urinary tract system and detaching host-derived copper, it thus protect against intracellular killing [58]. El Ghany et al characterized 10 carbapenem resistant UPEC isolates. They found that although these

isolates have different virulence structure; they nevertheless contained at least one iron system gene [2]. Serum resistance traits (tra $T$ and $c v a C$ genes) was the other important virulence factor that was found among these isolates. Toxin, protectin, and adhesion virulence factors were of lower importance. Although $58 \%$ of the isolates had the fimH gene, the evaluation of the presence of another 15 adhesion genes revealed that the acquisition or maintenance of these genes was less important for these bacteria. In contrast to our results, Ranjan et a/ reported that all five investigated NDM-harboring strains inherited genes belonging to adhesions and reflected moderate virulence [16].

Further studies are needed to determine what virulence factors are exist in carbapenem-resistant bacteria after gaining resistance. Perhaps a new treatment can be found to overcome these pathogens by targeting common biochemical pathways for the synthesis of proteins related to the virulence and resistance genes.

\section{Conclusion}

Antimicrobial resistance, especially resistance to carbapenems, is rapidly expanding. CR is easily transmitted to other bacteria through $\mathrm{HGT}_{\text {. The, }}$ bla $_{\mathrm{NDM}}$ followed by bla $a_{\mathrm{OXA}-48}$ were the most common cause of producing metallo-beta-lactamase and carbapenemase among the carbapenem-resistant isolates. Virulome analysis of these isolates revealed that the most of them reflected weak virulence; however, genes involved iron uptake genes especially siderophores were prevalent in the $\mathrm{CR}$ isolates. Understanding the spreading and pathogenicity in this group of emerging resistant bacteria can help to improve the therapeutic options and stewardship strategies in different regions.

\section{Abbreviations}

Uropathogenic Escherichia coli (UPEC); Urinary tract infection (UTI); Enterobacterial intergenic repetitive element sequence (ERIC); Extraintestinal pathogenic E. coli (ExPEC); Virulence Factor (VF); Unweighted Pair Group Method with Arithmetic Mean (UPGMA); Trypton soya broth (TSB); Antimicrobial resistance (AMR); Multi-drug resistant (MDR); Extensively-drug resistant (XDR); Pan-drug resistant (PDR); Carbapenem resistance (CR); Metallo- $\beta$-lactamases (MBLs); Klebsiella pneumoniae carbapenemase (KPC); Horizontal gene transfer (HGT); Eosin Methylene Blue (EMB); Clinical and Laboratory Standards Institute (CLSI); Combined disc test (CDT); Double disc synergy test (DDST); Modified carbapenem inactivation method (mCIM); EDTA-CIM (eCIM); Phenylboronic acid (PBA); dimethyl sulfoxide (DMSO); Enteroinvasive E. coli (EIEC); New Delhi metallo-beta-lactamase (NDM); Imipenemase (IMP); Verona integron-encoded metallobeta-lactamase (VIM); Oxacillinases (OXA); Extended-spectrum ß-lactamases (ESBLs); Sulfur Indole Motility (SIM); Methyl Red / Voges-Proskauer (MR/VP).

\section{Declarations}

\section{Competing interests}

The authors declare that they have no competing interests.

\section{Ethics approval and consent to participate}

The study was approved by Ethics Committee of Shahid Chamran University of Ahvaz (No: EE/98.24.3.26336/scu.ac.ir). Before collecting information, participants or parents (for children cases) were asked to read, accept and sign an informed consent form.

\section{Consent for publication}

Not applicable.

Availability of data and materials 
The datasets used and/or analyzed during the current study are available from the corresponding author on reasonable request. Sequence data of this project have been deposited in the GenBank of the National Center for Biotechnology Information (NCBI) under the accession number MT321108, MT321107, MT321106, and MT293867.

\section{Funding}

No funding.

\section{Authors' contributions}

All authors contributed to the design of the experiment. SER designed and supervised the research study. FZM and FM carried out the experiments. MRA and MRA participated in the design of the study. Data analysis was performed by MRA. All authors read and approved the final manuscript.

\section{Acknowledgements}

The authors are very thankful to Shahid Chamran University of Ahvaz for the facilities to accomplish the present research project (Grant Number: SCU.SB98.658). This study was related to MSc thesis of Fatemeh Zanganeh-Matin and Fahimeh Mahmoodi; however, Fatemeh Zanganeh-Matin has played a greater role in this work.

\section{Authors' Information}

Department of Biology, Faculty of Science, Shahid Chamran University of Ahvaz, Ahvaz, Iran

Seyedeh Elham Rezatofighi; Fatemeh Zanganeh-Matin; Mohammad Roayaei Ardakani; Fahimeh Mahmoodi

Mathematical Sciences and Computer Faculty, Shahid Chamran University of Ahvaz, Ahvaz, Iran

Mohammad Reza Akhoond

\section{References}

1. Ghadiri H, Vaez H, Razavi-Azarkhiavi K, Rezaee R, Haji-Noormohammadi M, Rahimi AA, et al. Prevalence and Antibiotic Susceptibility Patterns of Extended-Spectrum ß-Lactamase and Metallo-ß-Lactamase-Producing Uropathogenic Escherichia coli Isolates. Laboratory medicine. 2014;45:291-6.

2. Abd El Ghany M, Sharaf H, Al-Agamy MH, Shibl A, Hill-Cawthorne GA, Hong PY. Genomic characterization of NDM-1 and 5, and OXA-181 carbapenemases in uropathogenic Escherichia coli isolates from Riyadh, Saudi Arabia. PloS one 2018;13:e0201613.

3. Moreno E, Andreu A, Pigrau C, Kuskowski MA, Johnson JR, Prats G. Relationship between Escherichia coli strains causing acute cystitis in women and the fecal E. coli population of the host. J Clin Microbiol. 2008;46:2529-34.

4. Khairy RM, Mohamed ES, Abdel Ghany HM, Abdelrahim SS. Phylogenic classification and virulence genes profiles of uropathogenic E. coli and diarrhegenic $E$. coli strains isolated from community acquired infections. PloS one. 2019;14:e0222441.

5. Hossain M, Tabassum T, Rahman A, Hossain A, Afroze T, Momen AMI, et al. Genotype-phenotype correlation of $\beta$-lactamase-producing uropathogenic Escherichia coli (UPEC) strains from Bangladesh. Scientific reports. 2020;10:14549.

6. Wirth T, Falush D, Lan R, Colles F, Mensa P, Wieler LH, et al. Sex and virulence in Escherichia coli: an evolutionary perspective. Mol Microbiol. 2006;60:1136-51.

7. Wang M, Wang W, Niu Y, Liu T, Li L, Zhang M, et al. A Clinical Extensively-Drug Resistant (XDR) Escherichia coli and Role of Its $\beta$-Lactamase Genes. Frontiers in microbiology. 2020;11:590357.

8. Magiorakos AP, Srinivasan A, Carey RB, Carmeli Y, Falagas ME, Giske CG, et al. Multidrug-resistant, extensively drug-resistant and pandrug-resistant bacteria: an international expert proposal for interim standard definitions for acquired resistance. Clinical microbiology infection. 2012;18:268-81.

9. Bush K. Alarming $\beta$-lactamase-mediated resistance in multidrug-resistant Enterobacteriaceae. Curr Opin Microbiol. 2010;13:558-64.

10. Sanchez GV, Baird AM, Karlowsky JA, Master RN, Bordon JM. Nitrofurantoin retains antimicrobial activity against multidrug-resistant urinary Escherichia coli from US outpatients. J Antimicrob Chemother. 2014;69:3259-62.

11. Sanchez GV, Master RN, Karlowsky JA, Bordon JM. In vitro antimicrobial resistance of urinary Escherichia coli isolates among U.S. outpatients from 2000 to 2010. Antimicrob Agents Chemother. 2012;56:2181-3.

12. Singh T, Singh PK, Das S, Wani S, Jawed A, Dar SA. Transcriptome analysis of beta-lactamase genes in diarrheagenic Escherichia coli. Scientific reports. 2019;9:3626

13. Wang Q, Wang X, Wang J, Ouyang P, Jin C, Wang R, et al. Phenotypic and Genotypic Characterization of Carbapenem-resistant Enterobacteriaceae: Data From a Longitudinal Large-scale CRE Study in China (2012-2016). Clinical infectious diseases: an official publication of the Infectious Diseases Society of America. 2018;67:196-205.

14. Cole SD, Peak L, Tyson GH, Reimschuessel R, Ceric O, Rankin SC. New Delhi Metallo- $\beta$-Lactamase-5-Producing Escherichia coli in Companion Animals, United States. Emerg Infect Dis. 2020;26:381-3.

15. Khan AU, Maryam L, Zarrilli R, Structure. Genetics and Worldwide Spread of New Delhi Metallo- $\beta$-lactamase (NDM): a threat to public health. BMC microbiology. 2017;17:101. 
16. Ranjan A, Shaik S, Mondal A, Nandanwar N, Hussain A, Semmler T, et al. Molecular Epidemiology and Genome Dynamics of New Delhi Metallo- $\beta$ Lactamase-Producing Extraintestinal Pathogenic Escherichia coli Strains from India. Antimicrob Agents Chemother. 2016;60:6795-805.

17. Sfeir MM, Hayden JA, Fauntleroy KA, Mazur C, Johnson JK, Simner PJ, et al. EDTA-Modified Carbapenem Inactivation Method: a Phenotypic Method for Detecting Metallo- $\beta$-Lactamase-Producing Enterobacteriaceae. Journal of clinical microbiology 2019;57.

18. Chen J, Griffiths MW. PCR differentiation of Escherichia coli from other gram-negative bacteria using primers derived from the nucleotide sequences flanking the gene encoding the universal stress protein. Lett Appl Microbiol. 1998;27:369-71.

19. CLSI. Performance Standards for Antimicrobial Susceptibility Testing. 28th ed. CLSI supplement M100. Wayne: Clinical and Laboratory Standards Institute; 2018.

20. Picão RC, Andrade SS, Nicoletti AG, Campana EH, Moraes GC, Mendes RE, et al. Metallo- $\beta$-lactamase detection: comparative evaluation of double-disk synergy versus combined disk tests for IMP-, GIM-, SIM-, SPM-, or VIM-producing isolates. J Clin Microbiol. 2008;46:2028-37.

21. Tsakris A, Poulou A, Pournaras S, Voulgari E, Vrioni G, Themeli-Digalaki K, et al. A simple phenotypic method for the differentiation of metallo-betalactamases and class A KPC carbapenemases in Enterobacteriaceae clinical isolates. J Antimicrob Chemother. 2010;65:1664-71.

22. Tsakris A, Kristo I, Poulou A, Themeli-Digalaki K, Ikonomidis A, Petropoulou D, et al. Evaluation of boronic acid disk tests for differentiating KPCpossessing Klebsiella pneumoniae isolates in the clinical laboratory. J Clin Microbiol. 2009;47:362-7.

23. Shibata N, Doi Y, Yamane K, Yagi T, Kurokawa H, Shibayama K, et al. PCR typing of genetic determinants for metallo- $\beta$-lactamases and integrases carried by gram-negative bacteria isolated in Japan, with focus on the class 3 integron. J Clin Microbiol. 2003;41:5407-13.

24. Ellington MJ, Kistler J, Livermore DM, Woodford N. Multiplex PCR for rapid detection of genes encoding acquired metallo- $\beta$-lactamases. J Antimicrob Chemother. 2007;59:321-2.

25. Poirel L, Naas T, Nicolas D, Collet L, Bellais S, Cavallo J-D, et al. Characterization of VIM-2, a carbapenem-hydrolyzing metallo- $\beta$-lactamase and its plasmid-and integron-borne gene from a Pseudomonas aeruginosa clinical isolate in France. Antimicrob Agents Chemother. 2000;44:891-7.

26. Tsakris A, Pournaras S, Woodford N, Palepou M-FI, Babini GS, Douboyas J, et al. Outbreak of infections caused by Pseudomonas aeruginosa producing VIM-1 carbapenemase in Greece. J Clin Microbiol. 2000;38:1290-2.

27. Yong D, Toleman MA, Giske CG, Cho HS, Sundman K, Lee K, et al. Characterization of a new metallo- $\beta$-lactamase gene, blaNDM-1, and a novel erythromycin esterase gene carried on a unique genetic structure in Klebsiella pneumoniae sequence type 14 from India. Antimicrob Agents Chemother. 2009;53:5046-54.

28. Yigit H, Queenan AM, Anderson GJ, Domenech-Sanchez A, Biddle JW, Steward CD, et al. Novel carbapenem-hydrolyzing $\beta$-lactamase, KPC-1, from a carbapenem-resistant strain of Klebsiella pneumoniae. Antimicrob Agents Chemother. 2001;45:1151-61.

29. Donald HM, Scaife W, Amyes SG, Young H-K. Sequence Analysis of ARI-1, a Novel OXA $\beta$-Lactamase, Responsible for Imipenem Resistance in Acinetobacter baumannii 6B92. Antimicrob Agents Chemother. 2000;44:196-9.

30. Poirel L, Héritier C, Tolün V, Nordmann P. Emergence of oxacillinase-mediated resistance to imipenem in Klebsiella pneumoniae. Antimicrob Agents Chemother. 2004;48:15-22.

31. Johnson JR, Stell AL. Extended virulence genotypes of Escherichia coli strains from patients with urosepsis in relation to phylogeny and host compromise. The Journal of infectious diseases. 2000;181:261-72.

32. Clermont O, Bonacorsi S, Bingen E. Rapid and simple determination of the Escherichia coli phylogenetic group. Appl Environ Microbiol. 2000;66:4555-8.

33. Helalat H, Rezatofighi SE, Roayaei Ardakani M, Dos Santos LF, Askari Badouei M. Genotypic and phenotypic characterization of enteroaggregative Escherichia coli (EAEC) isolates from diarrheic children: An unresolved diagnostic paradigm exists. Iranian journal of basic medical sciences. 2020;23:915-21.

34. Mukherjee SK, Mukherjee M. Characterization and bio-typing of multidrug resistance plasmids from Uropathogenic Escherichia coli isolated from clinical setting. Frontiers in microbiology. 2019;10:2913.

35. Karam MRA, Habibi M, Bouzari S. Relationships between Virulence Factors and Antimicrobial Resistance among Escherichia coli Isolated from Urinary Tract Infections and Commensal Isolates in Tehran, Iran. Osong public health research perspectives. 2018;9:217-24.

36. Shahbazi S, Asadi Karam MR, Habibi M, Talebi A, Bouzari S. Distribution of extended-spectrum $\beta$-lactam, quinolone and carbapenem resistance genes, and genetic diversity among uropathogenic Escherichia coli isolates in Tehran, Iran. Journal of global antimicrobial resistance. 2018;14:118-25.

37. Malekzadegan $\mathrm{Y}$, Khashei $\mathrm{R}$, Sedigh $\mathrm{H}$, Jahanabadi Z. Distribution of virulence genes and their association with antimicrobial resistance among uropathogenic Escherichia coli isolates from Iranian patients. BMC Infectious Diseases 2018;18.

38. Haghighatpanah M, Mojtahedi A. Characterization of antibiotic resistance and virulence factors of Escherichia coli strains isolated from Iranian inpatients with urinary tract infections. Infection drug resistance. 2019;12:2747-54.

39. Souli M, Galani I, Giamarellou H. Emergence of extensively drug-resistant and pandrug-resistant Gram-negative bacilli in Europe. Euro surveillance 2008;13.

40. Cagnacci S, Gualco L, Roveta S, Mannelli S, Borgianni L, Docquier JD, et al. Bloodstream infections caused by multidrug-resistant Klebsiella pneumoniae producing the carbapenem-hydrolysing VIM-1 metallo-beta-lactamase: first Italian outbreak. J Antimicrob Chemother. 2008;61:296-300.

41. Souli M, Kontopidou FV, Papadomichelakis E, Galani I, Armaganidis A, Giamarellou H. Clinical experience of serious infections caused by Enterobacteriaceae producing VIM-1 metallo-beta-lactamase in a Greek University Hospital. Clinical infectious diseases 2008;46:847 - 54.

42. Göttig S, Riedel-Christ S, Saleh A, Kempf VA, Hamprecht A. Impact of bla $\mathrm{NDM}-1_{1}$ on fitness and pathogenicity of Escherichia coli and Klebsiella pneumoniae. Int J Antimicrob Agents. 2016;47:430-5. 
43. Yong D, Toleman MA, Giske CG, Cho HS, Sundman K, Lee K, et al. Characterization of a new metallo-beta-lactamase gene, bla(NDM-1), and a novel erythromycin esterase gene carried on a unique genetic structure in Klebsiella pneumoniae sequence type 14 from India. Antimicrob Agents Chemother. 2009;53:5046-54.

44. Mulvey MR, Grant JM, Plewes K, Roscoe D, Boyd DA. New Delhi metallo- $\beta$-lactamase in Klebsiella pneumoniae and Escherichia coli. Canada Emerging infectious diseases. 2011;17:103-6.

45. Kumarasamy KK, Toleman MA, Walsh TR, Bagaria J, Butt F, Balakrishnan R, et al. Emergence of a new antibiotic resistance mechanism in India, Pakistan, and the UK: a molecular, biological, and epidemiological study. The Lancet Infectious diseases. 2010;10:597-602.

46. Karthikeyan K, Thirunarayan MA, Krishnan P. Coexistence of bla $\mathrm{OXA}_{-23}$ with bla $\mathrm{NDM}_{-1}$ and armA in clinical isolates of Acinetobacter baumannii from India. J Antimicrob Chemother. 2010;65:2253-4.

47. Solgi H, Giske CG, Badmasti F, Aghamohammad S, Havaei SA, Sabeti S, et al. Emergence of carbapenem resistant Escherichia coli isolates producing $b / a_{\mathrm{NDM}}$ and bla $a_{\mathrm{OXA}-48}$-like carried on IncA/C and IncL/M plasmids at two Iranian university hospitals. Infection Genetics Evolution. 2017;55:318-23.

48. Fazeli H, Norouzi-Barough M, Ahadi A, Shokri D, Solgi H. Detection of New Delhi Metallo-Beta-Lactamase-1 (NDM-1) in carbapenem-resistant Klebsiella pneumoniae isolated from a university hospital in Iran. Hippokratia 2015;19:205.

49. Giamarellou H. Multidrug resistance in Gram-negative bacteria that produce extended-spectrum $\beta$-lactamases (ESBLs). Clinical Microbiology infection. 2005;11:1-16.

50. Shahcheraghi F, Nobari S, Rahmati Ghezelgeh F, Nasiri S, Owlia P, Nikbin VS, et al. First report of New Delhi metallo-beta-lactamase-1-producing Klebsiella pneumoniae in Iran. Microbial Drug Resistance. 2013;19:30-6.

51. Mahmoodi F, Rezatofighi SE, Akhoond MR. Antimicrobial resistance and metallo-beta-lactamase producing among commensal Escherichia coli isolates from healthy children of Khuzestan and Fars provinces; Iran. BMC microbiology. 2020;20:366.

52. Jamali S, Tavakoly T, Mojtahedi A, Shenagari M. The Phylogenetic Relatedness of b/a ${ }_{\mathrm{NDM}-1}$ Harboring Extended-Spectrum $\beta$-Lactamase Producing Uropathogenic Escherichia coli and Klebsiella pneumoniae in the North of Iran. Infection drug resistance. 2020;13:651.

53. Koraei M, Moosavian M, Saki M. Investigation of New Delhi metallo-beta-lactamase 1 (NDM-1) in clinical Enterobacteriaceae isolates in Southwest Iran. J Res Med Dent Sci. 2018;6:1-5.

54. Mombini S, Rezatofighi SE, Kiyani L, Motamedi H. Diversity and metallo- $\beta$-lactamase-producing genes in Pseudomonas aeruginosa strains isolated from filters of household water treatment systems. Journal of environmental management. 2019;231:413-8.

55. Deldar Abad Paskeh M, Mehdipour Moghaddam MJ, Salehi Z. Prevalence of plasmid-encoded carbapenemases in multi-drug resistant Escherichia coli from patients with urinary tract infection in northern Iran. Iranian journal of basic medical sciences. 2020;23:586-93.

56. Nojoomi F, Ghasemian A. Resistance and virulence factor determinants of carbapenem-resistant Escherichia coli clinical isolates in three hospitals in Tehran, Iran. Infection Epidemiology Microbiology. 2017;3:107-11.

57. Pitout JD, Peirano G, Kock MM, Strydom K-A, Matsumura Y. The global ascendency of OXA-48-type carbapenemases. Clinical microbiology reviews 2019;33.

58. Chaturvedi KS, Hung CS, Crowley JR, Stapleton AE, Henderson JP. The siderophore yersiniabactin binds copper to protect pathogens during infection. Nature chemical biology. 2012;8:731-6.

\section{Tables}

Table 1. Antimicrobial resistance profile of all uropathogenic Escherichia coli and carbapenem-resistant isolates

\begin{tabular}{|c|c|c|c|c|c|c|c|c|c|c|}
\hline $\begin{array}{l}\text { Category of } \\
\text { antibiotic }\end{array}$ & Quinolone & Penicillin & Tetracycline & Streptomycin & $\begin{array}{l}\text { Folate } \\
\text { pathway } \\
\text { inhibitors }\end{array}$ & Fluoroquinolone & Aminoglycoside & Aminoglycoside & $\begin{array}{l}\text { Phosphonic } \\
\text { acid }\end{array}$ & Carbapenem \\
\hline Antibiotic & $\begin{array}{l}\text { NA } \\
\text { N (\%) }\end{array}$ & AMP N (\%) & TET N (\%) & STR N (\%) & SXT N (\%) & CP N (\%) & K N (\%) & GM $\quad \mathrm{N}(\%)$ & FOS N (\%) & IMP N (\%) \\
\hline $\begin{array}{l}\text { UPEC } \\
\text { isolates }\end{array}$ & $240(59.1)$ & 334 (82.3) & $241(59.4)$ & $175(43.1)$ & $222(54.7)$ & $181(44.6)$ & $93(22.9)$ & $88(21.7)$ & 31 (7.6) & $11(2.7)$ \\
\hline $\begin{array}{l}\text { Carbapenem- } \\
\text { resistant } \\
\text { isolates }\end{array}$ & $12(100)$ & $12(100)$ & $10(83.3)$ & $10(83.3)$ & 11 (91.6) & $12(100)$ & 11 (91.6) & 11 (91.6) & $9 \quad(75)$ & 11 (91.6) \\
\hline
\end{tabular}

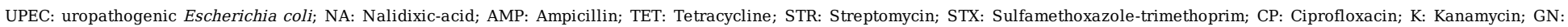
Gentamycin; FOS: Fosfomycin; IMP: Imipenem; MEN: Meropenem; CTX: Cefotaxime; CAZ: Ceftazidime; CZ: Cefazolin, FM: Nitrofurantoin

Table 2. Phenotypic and genotypic results of cabapenem-resistant uropathogeneic Escherichia coli isolates

\begin{tabular}{|c|c|c|c|c|c|c|c|c|c|c|c|c|c|c|c|c|}
\hline Test & $\begin{array}{l}\text { DDST N } \\
(\%)\end{array}$ & $\begin{array}{l}\text { CDT N } \\
\text { (\%) }\end{array}$ & $\begin{array}{l}\text { PBA N } \\
\text { (\%) }\end{array}$ & $\begin{array}{l}\mathrm{mCIM} N \\
(\%)\end{array}$ & $\begin{array}{l}\text { eCIM N } \\
(\%)\end{array}$ & $\begin{array}{l}b l a_{\mathrm{NDM}} \mathrm{N} \\
(\%)\end{array}$ & $\begin{array}{l}\text { bla }_{\text {IMP-1 }} \mathrm{N} \\
(\%)\end{array}$ & $\begin{array}{l}b l a_{\text {IMP-2 }} \mathrm{N} \\
(\%)\end{array}$ & $\begin{array}{l}\text { bla } a_{\mathrm{VIM}-1} \mathrm{~N} \\
\text { (\%) }\end{array}$ & $\begin{array}{l}b l a_{\text {VIM-2 }} \mathrm{N} \\
(\%)\end{array}$ & $\begin{array}{l}\text { bla }_{\text {SIM }} \mathrm{N} \\
(\%)\end{array}$ & $\begin{array}{l}b^{b l a}{ }_{\mathrm{GIM}} \mathrm{N} \\
(\%)\end{array}$ & $\begin{array}{l}b_{\text {SPM-1 }} \mathrm{N} \\
(\%)\end{array}$ & $b l a{ }_{\mathrm{kpc}} \mathrm{N}(\%)$ & $\begin{array}{l}b^{b l a} a_{\text {oxa- }} \\
{ }_{23} \mathrm{~N}(\%)\end{array}$ & $\begin{array}{l}b^{b l a} a_{\text {oxa- }} \\
{ }_{48} \mathrm{~N}(\%)\end{array}$ \\
\hline Sum & $6(50)$ & $8(66.7)$ & $2(16.7)$ & $12(100)$ & 11(91.6) & $9(75)$ & $1(8.3)$ & $1(8.3)$ & $0(0)$ & $0(0)$ & $0(0)$ & $0(0)$ & $0(0)$ & $0(0)$ & $0(0)$ & $5(41.7)$ \\
\hline
\end{tabular}


DDST: Double disc synergy test; CDT: Combined disc test; PBA: Phenylbronic acid disc test; mCIM: modified carbapenem inactivation method; eCIM: EDTA-CIM

Table 3. Frequency of virulence genes among carbapenem-resistant uropathogeneic Escherichia coli isolates

\begin{tabular}{|c|c|c|c|c|c|}
\hline Gene & $\mathrm{N}(\%)$ & Group of virulence trait & Number of detected genes $\mathrm{N}(\%)$ & Number of isolates with at least one virulence gene & N (\%) \\
\hline papEF & $0(0)$ & & & & \\
\hline papA & $2(16.7)$ & & & & \\
\hline fimH & $7(58.3)$ & & & & \\
\hline papG allele I-III & $2(16.7)$ & & & & \\
\hline papG allele $I$ & $0(0)$ & & & & \\
\hline papG allele II & $2(16.7)$ & & & & \\
\hline papG allele III & $0(0)$ & adhesions & $16(7.8 \%)$ & $8(66.7)$ & \\
\hline kspMTIII & $0(0)$ & & & & \\
\hline gafD & $0(0)$ & & & & \\
\hline focG & $0(0)$ & & & & \\
\hline$s f a / f o c D E$ & $0(0)$ & & & & \\
\hline$n f a E$ & $0(0)$ & & & & \\
\hline papC & $3(25)$ & & & & \\
\hline$a f a / d r a B C$ & $0(0)$ & & & & \\
\hline sfas & $0(0)$ & & & & \\
\hline$b m a E$ & $0(0)$ & & & & \\
\hline ibeA & $0(0)$ & invasion & $0(0)$ & $0(0)$ & \\
\hline $\operatorname{traT}$ & $8(66.7)$ & serum resistance & $9(37.5)$ & $8(66.7)$ & \\
\hline cva $C$ & $1(8.3)$ & & & & \\
\hline$c d t B$ & $0(0)$ & & & & \\
\hline hlyA & $2(16.7)$ & toxin & $4(11.1)$ & $3(25)$ & \\
\hline cnf1 & $2(16.7)$ & & & & \\
\hline fyuA & $8(66.7)$ & & & & \\
\hline $\operatorname{chuA}$ & $5(41.7)$ & siderophore & $20(55.5)$ & $9(75)$ & \\
\hline iutA & 7 (58.3) & & & & \\
\hline$K 1$ & $0(0)$ & & & & \\
\hline$K 5$ & $2(16.7)$ & protectin & $5(10.4)$ & $3(25)$ & \\
\hline kpsMTII & $3(25)$ & & & & \\
\hline$r f C$ & $0(0)$ & & & & \\
\hline PAI & $3(25)$ & pathogenic island & $3(25)$ & $3(25)$ & \\
\hline $\mathrm{A}$ & $5(41.7)$ & & & & \\
\hline B1 & $1(8.3)$ & & & & \\
\hline B2 & $5(41.7)$ & phylogroup & & & \\
\hline $\mathrm{D}$ & $1(8.3)$ & & & & \\
\hline
\end{tabular}

Table 4. Virulence genes and antimicrobial resistance scores of carbapenem-resistant uropathogenic Escherichia coli isolates 


\begin{tabular}{|c|c|c|c|c|}
\hline \multirow[t]{2}{*}{ Name } & \multirow{2}{*}{$\begin{array}{c}\text { Score of VG } \\
(\mathrm{N}=30) \text { Mean: } 4.3\end{array}$} & \multicolumn{2}{|c|}{ Score of AMR } & \multirow[t]{2}{*}{ Detected resistance genes } \\
\hline & & $(\mathrm{N}=15)$ & Mean: 13.25 & \\
\hline 3 & 6 & & 12 & bla $_{\mathrm{NDM}^{-}}-b l a_{\mathrm{OXA}-48}$ \\
\hline 4 & 10 & & 15 & $b l a_{\mathrm{NDM}^{-}}-b l a_{\mathrm{OXA}-48}$ \\
\hline 6 & 3 & & 14 & $b l a_{\mathrm{NDM}^{-}}-b l a_{\mathrm{OXA}-48}$ \\
\hline 8 & 5 & & 12 & $b l a_{\mathrm{NDM}^{-}}-b l a_{\mathrm{OXA}-48}$ \\
\hline 10 & 10 & & 11 & $b l a_{\text {IMP-2 }}$ \\
\hline 14 & 3 & & 15 & $b l a_{\mathrm{OXA}-48}$ \\
\hline 18 & 3 & & 10 & $b l a_{\mathrm{NDM}}$ \\
\hline 23 & 4 & & 15 & $b l a_{\mathrm{NDM}}$ \\
\hline 47 & 0 & & 15 & $b l a_{\text {IMP-1 }}$ \\
\hline 76 & 6 & & 13 & $b l a_{\mathrm{NDM}}$ \\
\hline 176 & 2 & & 15 & $b l a_{\mathrm{NDM}}$ \\
\hline 303 & 0 & & 12 & $b l a_{\mathrm{NDM}}$ \\
\hline
\end{tabular}

VG: virulence gene; AMR: antimicrobial resistance

\section{Figures}
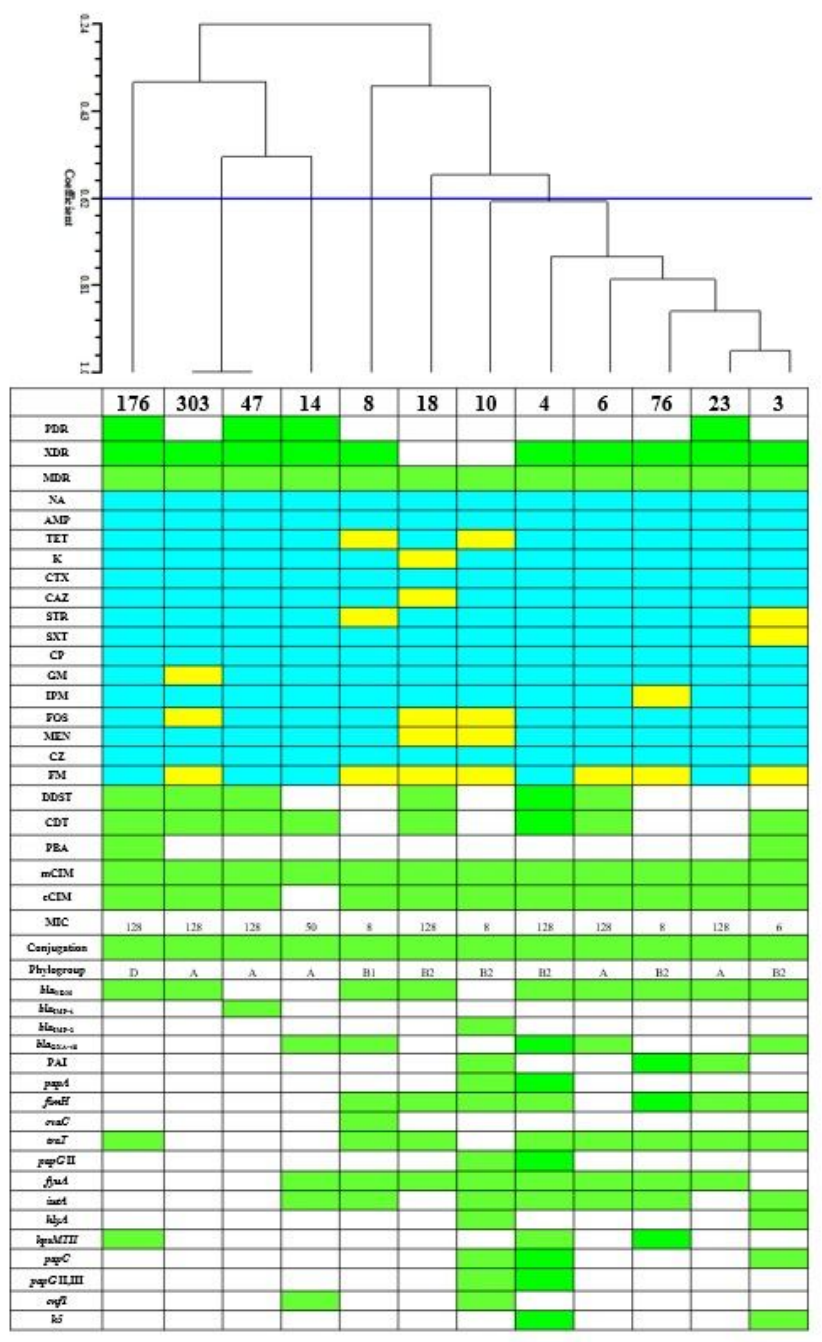

\section{Figure 1}

ERIC-PCR clustering and all phenotypic and genotypic characters of carbapenem-resistant UPEC isolates. blaVIM-1, blaVIM-2, blaSIM, blaSPM, blaGIM, blaOXA-23, blaKPC, kpsMTIII, papEF, ibeA, gafD, cdtB, focG, bmaE, sfa/focDE, papG allel I, II, and III, K1, rfc, nfaE, sfaS, and afa/draBC genes were not found; therefore were not shown. Blue and yellow colors indicate resistance and susceptibility, respectively. Green color shows presence of gene or phenotypic character and white color indicates absence of gene or phenotypic character. Abbreviations were as follow: PDR: Pan-drug resistant; XDR: Extensively-drug 
resistant; MDR: Multi-drug resistant; NA: Nalidixic-acid; AMP: Ampicillin; TET: Tetracycline; STR: Streptomycin; STX: Sulfamethoxazole-trimethoprim; CP: Ciprofloxacin; K: Kanamycin; GN: Gentamycin; FOS: Fosfomycin; IMP: Imipenem; MEN: Meropenem; CTX: Cefotaxime; CAZ: Ceftazidime; CZ: Cefazolin, FM: Nitrofurantoin; DDST: Double disc synergy test; CDT: Combined disc test; PBA: Phenylbronic acid disc test; mCIM: modified carbapenem inactivation method; eCIM: EDTA-CIM; MIC: Minimum inhibitory concentration 